zusammen in ein Gefäss, mengt sie darin innig untereinander und lässt das Ganze fest werden (Annal. de la Soc. polytechn. Nr. 10. Dingl. polytechn. Journ. LI. 155).

\title{
Tünche für Packtücher, Rollvorhänge und Stricke.
}

I Pfund Kautschnk, 1 Pfund Steinkoblentheer, 2 Pfund Leinöl, I Pfund fettes Oel und $\frac{1}{2}$ Pfund Bleiglätte werden geschmolzen; man nimmt die Masse darauf vom Feuer, zu Vermeidung der Feuersgefahr, und setzt ihr $\frac{T}{2}$ Pfund Terpentinöl zu. Besser ist noch statt der Bleiglätte $\frac{x}{2}$ Pfund Bleizucker und 1 Pfund Braunstein zu nehmen (Journ. d. connoiss. usuell. 1834. 38).

\section{F ü $n$ f $t$ e $A$ b t he i l u $n$ g.}

Allgemeine und pharrenceutische Naturgeschichte und Pharmakognosie.

Ueber die Bildung der Lagen von Schwefel und Gyps;

$$
\text { Charles Metteucci. }
$$

(Auszug aus den Annales de Chim. et de Phys. LV. 313).

Die Depots, welche die Erdrinde constituiren, theilen sich in zwei distincte. Klassen. In der einen findet man eine grosse Menge krystallinischer Felsen, fast gänzlich aus Silikaten gebildet, ohne organische Reste und ohne sandige Materien. In der andern zeigen sich zwar auch einige der vori- 